\title{
AS HORTAS URBANAS COMO UMA CONTRIBUIÇÃO ÀS CIDADES SUSTENTÁVEIS: O CASO DO GRAMOREZINHO EM NATAL/RN
}

Camila Bezerra Nobre de Medeiros ${ }^{1}$

Miss Lene Pereira da Silva ${ }^{2}$

Ruth Maria da Costa Ataíde ${ }^{3}$

\begin{abstract}
RESUMO Embora seja considerado um município completamente urbano, Natal possui ilhas de ruralidade em seu território, caracterizadas pela produção agrícola e por um modo de vida que remete ao campo. Exemplo disto é o Gramorezinho, comunidade localizada no bairro Lagoa Azul. Tendo em vista a crescente discussão sobre a agricultura urbana e a sua importância para a construção de cidades sustentáveis, o artigo objetiva refletir sobre o papel do Gramorezinho para a sustentabilidade socioambiental em Natal. A metodologia adotada consistiu na revisão bibliográfica sobre os conceitos de sustentabilidade e agricultura urbanas, visitas de campo, reuniões com os moradores e coleta de dados secundários sobre o Gramorezinho. Na pesquisa, foi verificado que a área possui grande potencial paisagístico, ambiental, cultural e aspectos sociais e econômicos relevantes, sendo um exemplo de como atividades econômicas podem se desenvolver em consonância com a proteção ambiental. No entanto, foram constatadas demandas por serviços e melhorias de infraestrutura na comunidade, bem como a urgência de regulamentação da Zona de Proteção Ambiental em que ela se insere e do próprio Gramorezinho como Área Especial de Interesse Social voltada para a Segurança Alimentar. A regulamentação permitirá o reconhecimento legal da área e facilitará a provisão de infraestrutura para a mesma, garantindo a permanência de seus moradores e a continuidade da atividade agrícola no local.
\end{abstract}

PALAVRAS-CHAVE: Sustentabilidade Urbana. Agricultura Urbana. Hortas Urbanas.

\footnotetext{
${ }^{1}$ Arquiteta e Urbanista, mestranda do programa de pós-graduação em Arquitetura e Urbanismo da UFRN.cabnob@gmail.com.

${ }^{2}$ Arquiteta e Urbanista, mestranda do programa de pós-graduação em Arquitetura e Urbanismo da UFRN. Professora de Planejamento e Projeto Urbano em Arquitetura e Urbanismo pela Universidade Potiguar.misslenep@gmail.com.

${ }^{3}$ Arquiteta e Urbanista, Dra em Pensamiento Geografico y Organización del Territorio pela Universidade de Barcelona, professora e pesquisadora de graduação e do programa de pósgraduação em Arquitetura e Urbanismo da UFRN. rataide_58@hotmail.com.
} 


\title{
THE URBAN GARDENS AS A CONTRIBUTION TO SUSTAINABLE CITIES: The GRAMOREZINHO CASE IN
}

\author{
NATAL / RN
}

\begin{abstract}
Natal is considered to be completely urbanized; however its territory contains rurality islands. One example that illustrates this statement is the community Gramorezinho, located in a neighbourhood called Lagoa Azul. Considering the recent debates regarding the role of urban agriculture to the construction of sustainable cities, this article aims to examine about Gramorezinhos' importance to the social and environmental sustainability in Natal. The methodology consisted in a literature review about urban sustainability and urban agriculture, field trips and consulting secondary data about Gramorezinho. The research verified that the area has a great landscape, environmental and cultural potential as well as social and economic relevant aspects, being a good example of how economic activities can be in consonance with environmental protection. However, the need for infrastructure and services improvements was detected as well as the urgency for the regulation of the Environmental Protection Zone where the community endures and the regulation of Gramorezinho as an Especial Area of Social Interest of Food Safety. The regulation can contribute to the legal recognition of the area and favour its infrastructure improvement, guaranteeing the permanence of its inhabitants and the continuance of the agriculture's practice.
\end{abstract}

\section{LOS JARDINES URBANOS COMO CONTRIBUCIÓN A CIUDADES SOSTENIBLES: EI CASO GRAMOREZINHO en Natal / RN}

\begin{abstract}
RESUMEN Aunque se considere un municipio totalmente urbano, Natal tiene islas de ruralidad en su territorio, caracterizado por la producción agrícola y un modo de vida similar al campo. Ejemplo de ello es el Gramorezinho, comunidad ubicada en el barrio de Lagoa Azul. En razón del creciente debate respecto a la agricultura urbana y su importancia para construir ciudades sostenibles, el artículo pretende reflexionar sobre el papel del Gramorezinho para la sostenibilidad social y ambiental en Natal.La metodología adoptada consistió en la revisión bibliográfica sobre los conceptos de sostenibilidad y agricultura urbana, visitas de campo, reuniones con los residentes y recopilación de datos secundarios sobre Gramorezinho. En la encuesta, se encontró que el área tiene grandes potenciales ambientales, culturales y relevantes aspectos socio-económicos, siendo un ejemplo de como las actividades económicas puede desarrollarse en consonancia con la protección del medio. Sin embargo, se confirmaron las demandas de servicios y mejoras en la infraestructura de la comunidad, así como la urgencia de regularización urbanística de la Zona de Protección Ambiental en la que se inserta, además del mismo Gramorezinho como Área Especial de interés Social (AEIS) de seguridad alimentaria. La regularización urbanística permitirá el reconocimiento legal del área y facilitará el suministro de infraestructura, asegurando la permanencia de sus residentes y la continuación de la actividad agrícola en el mismo sitio.
\end{abstract}

PALABRAS-CLABE: Ciudades Sostenibles. Agricultura Urbana. Huertos Urbanos. 


\section{Cidad}

Um dos desafios das cidades contemporâneas é lidar com as crescentes taxas de urbanização. Com o aumento da população urbana, cresce também a pressão da ocupação sobre os recursos naturais e a demanda por infraestrutura, serviços e atendimento às necessidades básicas dos habitantes das cidades.

A apropriação do conceito de desenvolvimento sustentável tem sido apontada como uma das estratégias para enfrentar esses desafios e incorporada às cidades com denominações variadas: cidades sustentáveis, cidades ecológicas, ecocities, urbanismo sustentável e urbanismo ecológico. Diversos autores têm tratado do tema, apresentando reflexões sobre o conceito e sobre iniciativas locais que tentam incorporá-lo na prática.

A agricultura urbana tem sido uma dessas iniciativas associada à busca da sustentabilidade nas cidades. A sua prática em espaços urbanos e periurbanos pode objetivar a segurança alimentar, a geração de renda, a inclusão social e as interações socioambientais, além de contribuir para o aumento dos espaços verdes urbanos. Uma das formas mais comuns de se praticar a agricultura na cidade é através do cultivo de hortas urbanas, que se constituem como novas formas de uso e apropriação de terrenos públicos ou privados, para o cultivo de hortaliças, no interior ou nas periferias das cidades.

De acordo com Alain Santandreu e Ivana Lovo (2007), a Agricultura Urbana e Periurbana (AUP) é praticada em todas as regiões do Brasil, abarcando grande diversidade de contextos. Na cidade de Natal, capital do Rio Grande do Norte, há um exemplo singular de uma comunidade dedicada à agricultura urbana e especificamente à produção de hortaliças: o Gramorezinho, localizado na Região Administrativa Norte de Natal (RANorte), no bairro de Lagoa Azul, e que ali reside há cerca de 40 anos. A comunidade se caracteriza como uma ilha de ruralidade no meio urbano e estabelece importantes relações com o ecossistema natural do meio físico onde está inserida, uma Zona de Proteção Ambiental (ZPA9), caracterizada pela forte presença de dunas e lagoas. 
Nesse contexto, o presente artigo tem por objetivo refletir sobre o papel do Gramorezinho para a sustentabilidade urbana em Natal, sob a ótica do planejamento urbano. Para tanto, recorreu-se a alguns procedimentos metodológicos que incluíram revisão bibliográfica sobre os conceitos de sustentabilidade urbana e agricultura urbana e hortas urbanas, visitas de campo e reuniões com os moradores 4 e coleta de dados secundários sobre o bairro e a população residente.

O artigo se encontra estruturado em quatro partes: reflexões sobre a sustentabilidade urbana, discussões sobre a produção agrícola nas cidades e as hortas urbanas e as singularidades do Gramorezinho, tecendo uma análise da área, e por fim, abordando as devidas contribuições sobre a promoção da sustentabilidade urbana em Natal.

\section{REFLEXÕES SOBRE A SUSTENTABILIDADE URBANA}

De acordo com a Organização das Nações Unidas, desde 2007 a população mundial é predominantemente urbana (UNITED NATIONS, 2014). Proporcionar qualidade de vida ao contingente populacional que se dirige às cidades é, portanto, uma questão que merece reflexões.

Um conceito que tem sido amplamente debatido e que contribui para a discussão é o de cidades sustentáveis. No entanto, para iniciar a discussão sobre cidades sustentáveis - ou urbanismo sustentável - é necessário compreender o conceito de sustentabilidade.

O termo "sustentabilidade" ganhou notoriedade no relatório Our Common Future $^{5}$, que definiu o conceito de desenvolvimento sustentável como sendo aquele que atende as necessidades das gerações atuais sem comprometer a capacidade de as gerações futuras atenderem as suas próprias necessidades. Sustentabilidade

\footnotetext{
${ }^{4}$ Realizadas para o Projeto de Extensão "Agricultura Urbana, Geração de Renda e Sustentabilidade na Zona de Proteção Ambiental 9 (ZPA 9) nos municípios de Natal e Extremoz", do departamento de Geografia da UFRN.

${ }^{5}$ Em português, Nosso Futuro Comum, também conhecido como Relatório Brundtland, elaborado pela Comissão Mundial sobre o Meio Ambiente e o Desenvolvimento criada pela Organização das Nações Unidas (1987).
} 
tem, portanto, relação com ação de sustentar, no sentido de permitir a continuidade da vida na Terra e, assim sendo, é um conceito amplo, que abarca diferentes dimensões.

Para Washington Novaes (2000), há cinco dimensões para a sustentabilidade: ambiental, ligada à capacidade dos ecossistemas de recomposição após impacto; social, relacionada ao atendimento das necessidades básicas dos seres humanos; política, vinculada à garantia da cidadania e da participação em processos decisórios; econômica, referente à gestão adequada dos recursos; demográfica, relativa à capacidade de suporte dos territórios e da sua base de recursos; cultural, relacionada à capacidade de manter a diversidade de culturas no planeta e, por fim, espacial, ligada à busca por um maior equilíbrio nas relações inter-regionais.

$\mathrm{Na}$ visão de Henri Acselrad (2009), diversas matrizes discursivas têm sido associadas ao conceito de sustentabilidade. Dentre estas matrizes se destacam a da eficiência, que visa combater o desperdício de recursos; a da escala, que impõe limites ao crescimento econômico e a consequente pressão sobre os recursos ambientais; a da equidade, que relaciona justiça social e ecologia; a da autossuficiência, que prega uma maior autonomia das economias nacionais em relação ao mercado mundial; e a da ética, que envolve uma discussão sobre valores morais que devem nortear a continuidade do desenvolvimento.

Um aspecto importante levantado por Acselrad é a aplicação da ideia de sustentabilidade às condições de reprodução da legitimidade das políticas urbanas. Isto significa atender às demandas sociais por serviços urbanos através da promoção de políticas públicas. O não atendimento destas demandas poderá acarretar na fragilização das bases de legitimidade dos gestores urbanos e em conflitos e incertezas no processo de reprodução e durabilidade das cidades, ou seja, na sua capacidade de se sustentar. Para esse autor, a sustentabilidade é um conceito que aponta para o futuro e, por isso, é ainda não existente. Consequentemente, diferentes discursos são postos em disputa pela definição das noções de sustentabilidade, ocasionado uma luta simbólica pelo reconhecimento da autoridade para discorrer sobre o tema. 
Uma das áreas do conhecimento que assimilou o conceito de sustentabilidade foi o urbanismo, que se debruça sobre o processo de constituição das cidades e suas dinâmicas de crescimento e desenvolvimento. Na perspectiva da sustentabilidade, alguns autores têm procurado aprofundar as noções de cidades sustentáveis.

Douglas Farr é um dos autores que trata do conceito de urbanismo sustentável. Para Farr (2013), para que se promova um urbanismo sustentável é necessário observar quatro aspectos principais: compacidade, que consiste em aumentar a densidade urbana; completude, que significa promover diversidade de usos e de arquitetura nas cidades; conectividade, que consiste na integração entre transporte e uso do solo e, por último, a biofilia, como a promoção de interações sustentáveis entre homem e meio natural. Os aspectos levantados pelo autor têm impacto uns nos outros quando postos em prática. Por exemplo, ao construir cidades mais densas a proteção de áreas verdes é facilitada, devido à contensão da expansão urbana. Ao mesmo tempo, os serviços se encontrarão próximos uns aos outros e, quando diversos, facilitarão deslocamentos a pé e de bicicleta, contribuindo para a vitalidade urbana. A prioridade de investimentos no transporte público também auxilia na proteção de áreas verdes, visto que o planejamento voltado para automóveis ocupa mais espaço nas cidades.

Cecília Herzog (2013), por sua vez, trabalha com o conceito de ecologia urbana e o define como o estudo das relações de todos os seres vivos que habitam o meio urbano entre eles e deles com a cidade. Um dos pilares da discussão é a infraestrutura verde, composta pelos sistemas naturais e antrópicos. Os sistemas naturais são constituídos pelos sistemas geológico, hidrológico e biológico e os sistemas antrópicos pelos sistemas social, circulatório e metabólico. Cada um destes subsistemas apresenta uma série de desafios a serem enfrentados para a construção de uma cidade ecológica. O sistema geológico, por exemplo, apresenta como desafios a erosão, os deslizamentos, a limitação da capacidade de suporte e o desgaste do solo. Já o sistema hidrológico lida com a questão dos alagamentos, má qualidade da água, chuva ácida e acesso a água potável. O sistema biológico, por 
sua vez, tem como desafios o desmatamento, a pressão sobre reservas naturais e o risco de extinção de espécies.

No que diz respeito aos sistemas antrópicos, o sistema social apresenta como desafios a monotonia dos espaços urbanos, a exclusão social, a falta de acessibilidade, a promoção da qualidade de vida e o fortalecimento da identidade e cultura. Já o sistema circulatório, que diz respeito à mobilidade urbana, necessita buscar a diminuição da dependência do automóvel, a promoção do transporte público de qualidade e a valorização dos meios de transporte não motorizados e do pedestre. Por fim, o sistema metabólico (matéria e energia necessárias para manter - ecossistema urbano), deve focar na busca por outras fontes de energia, tratamento adequado de resíduos e no acesso a alimentos saudáveis e baratos.

Para Herzog (2013), há duas maneiras possíveis de se chegar a cidades sustentáveis: melhorar o espaço já existente ou criar novas cidades ou bairros ecológicos. A melhoria de espaços já existentes, através de diferentes ações, dialoga com o conceito de acupuntura urbana, elaborado por Jaime Lerner (2011). De acordo com este autor, espaços urbanos podem ser modificados de tal maneira a provocarem reações positivas e em cadeia. Uma das intervenções urbanas que apresentam potencial para modificar as cidades, alinhando-as com o conceito da sustentabilidade e, possivelmente, gerando efeitos positivos em seu entorno e irradiando-os, são as hortas urbanas comunitárias.

\section{A PRODUÇÃO AGRÍCOLA NAS CIDADES E AS HORTAS URBANAS}

A agricultura é definida, segundo Isabel Maria Madaleno (2002), como a soma de tarefas capazes de transformar o meio natural para produzir matérias vegetais e criar animais úteis ao homem. Na visão de Luc Mougeot (2000), a agricultura urbana se diferencia da rural por estar integrada com o sistema econômico e ecológico urbano, denominado ecossistema urbano. De acordo com este autor, a agricultura urbana pode ser classificada a partir dos seguintes critérios: tipos de atividades econômicas envolvidas, do plantio ao processamento; 
localização intraurbana (dentro das cidades) ou periurbanas (áreas periféricas e próximas aos centros urbanos); tipos de áreas onde é praticada, variando de acordo com o uso do solo e com as diferentes modalidades de posse do terreno; sistema e escala de produção; categorias e subcategorias de produtos (alimentícios ou não) e a sua destinação, para autoconsumo e/ou comércio.

Apesar da visibilidade recente, a agricultura urbana não é um conceito novo. Herzog (2013) aponta que a produção de alimentos dentro da cidade data do século XIX. Os migrantes do campo recém-inseridos no mercado de trabalho urbano reivindicavam pequenos lotes para cultivar alimentos tanto para autoconsumo quanto para manterem o contato com a terra. Um exemplo dessa prática são os Jardins Ouvriers, ou Jardins Operários, na França: espaços em que pequenos lotes podiam ser alugados para o cultivo. Outro exemplo citado são os Victory Gardens, ou Jardins da Vitória, nos Estados Unidos, criados com objetivo de suprir a escassez de comida ocasionada pela Primeira Guerra Mundial.

Atualmente a prática da agricultura urbana ocorre nos mais diversos locais do globo motivadas por diferentes razões. Para Miriam Zaar (2011), não se pode afirmar que os motivos que levam europeus e latino-americanos a praticarem a agricultura nas cidades sejam exatamente os mesmos, mas se pode dizer que em ambas as localidades há uma porcentagem de cidadãos que atuam com objetivos idênticos. Na América Latina, há uma tendência do plantio relacionado à sobrevivência, porém, há também grupos que cultivam com outros objetivos: reconexão com a natureza e com a terra, ocupação de espaços ociosos ou preocupação com a alimentação, como é o caso das hortas cultivadas pelo grupo "Hortelões Urbanos" de São Paulo (Figura 1). 


\section{actores Cidades Verdes}

Figura 1: Horta na Praça do Ciclista, Avenida Paulista.

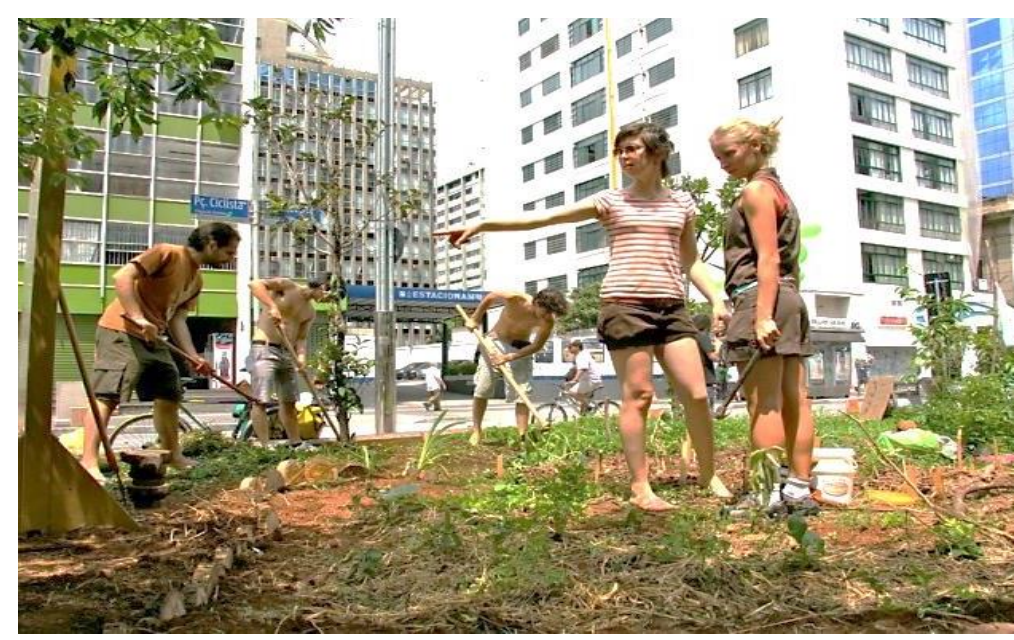

Fonte: Fernanda Danelon, 2012.

A agricultura urbana permite reflexões sobre a integração entre os conceitos de urbanidade e ruralidade, entendidas aqui como os valores e qualidades, ligadas respectivamente à cidade e ao campo, porém não necessariamente restritas a estes espaços. Assim, a urbanidade está ligada à concentração espacial de uma diversidade de serviços e atividades, por exemplo, enquanto a ruralidade se conecta com valores como a tranquilidade, presença abundante da natureza e à tradição.

Como os conceitos não se restringem aos espaços em que se inserem, ilhas de ruralidade "pura" podem ser encontradas no meio urbano, definidas por Henri Lefebvre (2001, p. 19), como "torrões natais frequentemente pobres, povoados por camponeses envelhecidos, mal 'adaptados', despojados daquilo que constitui a nobreza da vida camponesa nos tempos de maior miséria e da opressão". Esta definição se adequa bem à prática da agricultura como estratégia de sobrevivência de grupos sociais vulneráveis nas cidades.

Para Dorothée Imbert (2014), a agricultura urbana foi redescoberta como um equivalente fácil e de baixo custo frente a outras tecnologias. A iniciativa possui diversos aspectos que podem contribuir para a sustentabilidade urbana: criação de empregos, geração de renda e fortalecimento do mercado local; aprimoramento da 
segurança alimentar; fortalecimento de comunidades; redução das food miles ${ }^{6}$; resgate da cultura do campo e do contato com a terra; contribuições para a educação ambiental, terapia e ressocialização; ocupação de terrenos ociosos; ampliação de áreas verdes; diversificação do uso do solo e multifuncionalidade ${ }^{7}$.

Uma das expressões mais populares da agricultura urbana nas cidades são as hortas urbanas. De acordo com Rute Pinto (2007), o verbete horta vem da palavra hortus que designa um pedaço de terra anexo à residência romana, no qual se cultiva alimentos para o consumo familiar. Atualmente, a definição de horta é a de qualquer espaço destinado ao cultivo de hortaliças ${ }^{8}$ e de outras plantas, como ervas condimentares e aromáticas. As hortas urbanas são, portanto, espaços destinados ao cultivo de hortaliças no espaço urbano ou em suas proximidades, objetivando o autoconsumo ou a comercialização. Tais hortas podem se localizar tanto em espaços privados quanto públicos, como quintais, pátios, terrenos livres, jardins, estruturas da edificação, canteiros, calçadas, praças, parques e abaixo de linhas de transmissão de energia. Além disso, as hortas podem ocorrer por iniciativas individuais, familiares, comunitárias, de empresas, instituições, ONGs e órgãos públicos.

Recomenda-se que o processo produtivo utilizado nas hortas seja guiado por princípios da agroecologia ${ }^{9}$ para que se dialogue com 0 conceito da sustentabilidade. A agricultura orgânica é uma prática da agroecologia e tem sido utilizada recentemente como modo de produção na comunidade do Gramorezinho, que será analisada na próxima seção.

\section{AS SINGULARIDADES DO GRAMOREZINHO}

\footnotetext{
${ }^{6}$ Distância percorrida por um alimento até chegar à mesa do consumidor. Quanto maior o seu valor, maior a emissão de gases poluentes e maiores o impactos ambientais vinculados ao produto.

${ }^{7}$ Nas proximidades de Paris, por exemplo, plantações de cereais são combinadas com atividades de lazer.

${ }^{8}$ Plantas de pequeno porte classificadas em verduras, legumes e plantas de fruto.

${ }^{9}$ Estudo da agricultura a partir de uma perspectiva ecológica, focando nas relações socioambientais e culturais.
} 
O Gramorezinho é uma comunidade que se localiza no bairro de Lagoa Azul, na cidade de Natal/RN, ao longo da Avenida Moema Tinoco da Cunha Lima. A comunidade se configura como uma ilha de ruralidade marcada pela intensa produção de hortaliças nos quintais das residências, sendo por isso também conhecida como "Cinturão verde da Grande Natal" (Figura 2). Na definição do Plano Diretor de Natal, a Zona de Proteção Ambiental é uma área cujas características do meio físico restringem o uso e a ocupação do solo e que pode ser dividida em três subzonas: Subzona de Preservação (SP), Subzona de Conservação (SC) e Subzona de Uso Restrito (SUR). Há uma hierarquia de possibilidades de uso nestas subzonas, sendo a mais restrita a da SP e a menos restrita a SUR. O Gramorezinho se encontra nas "SP" e "SC" sugeridas para a ZPA 9, que se encontra em processo de regulamentação (Figura 2).

Figura 2: Localização das Hortas do Gramorezinho e Zoneamento Ambiental da ZPA9.

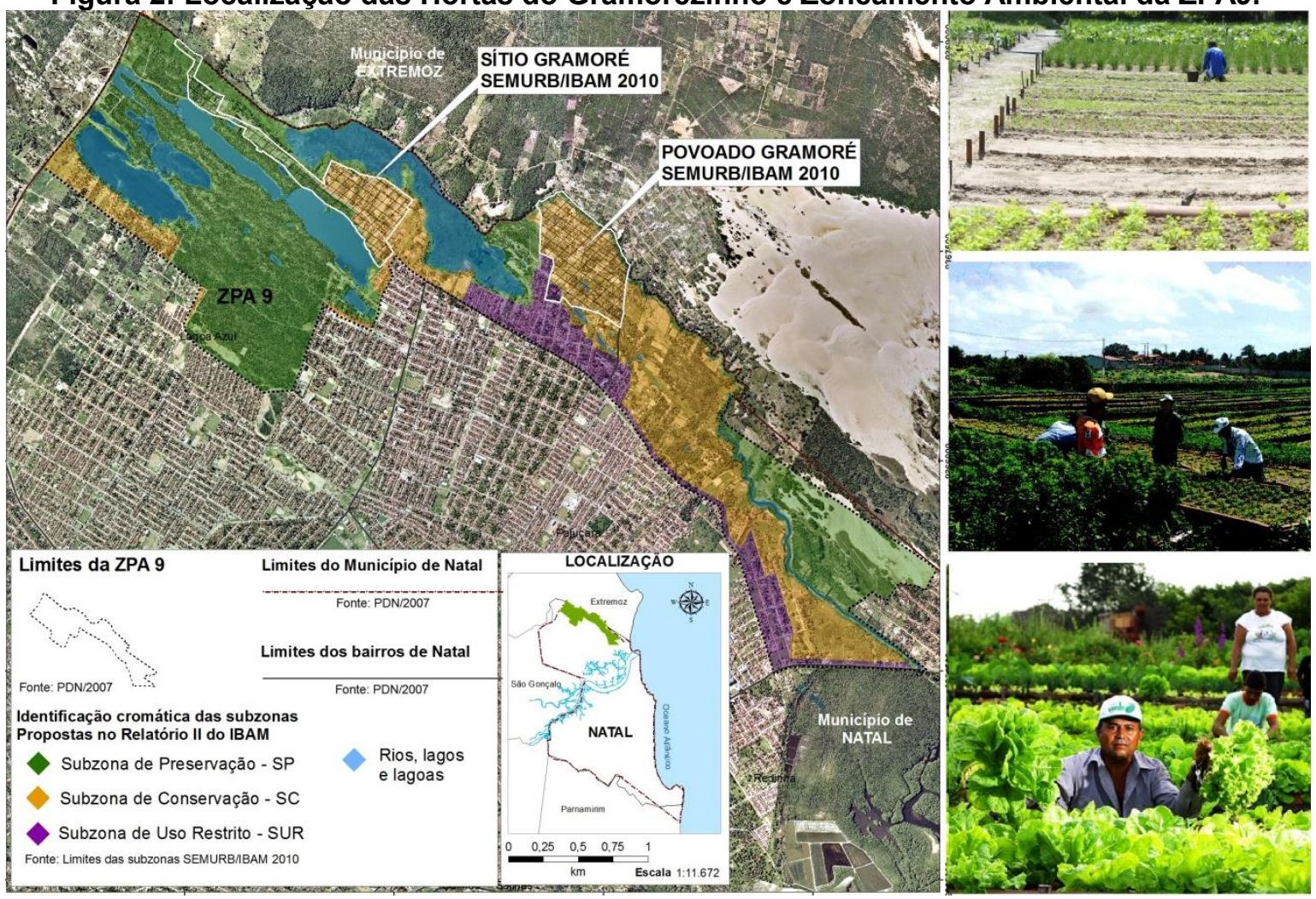

Fonte: Mapa MPRN, 2012. Fotos SEBRAE RN 2015. Modificado pelas autoras. 
As hortaliças são produzidas principalmente para comercialização e constituem a principal fonte de renda da maior parte das famílias que se dedicam ao cultivo na comunidade. De acordo com Maria Conceição Américo (2006), a renda média de mais de $90 \%$ da comunidade varia de 0 a 3 salários mínimos. Do ponto de vista ambiental, o Gramorezinho possui abundância de recursos naturais e potencial cênico-paisagístico, uma vez que se insere na Zona de Proteção Ambiental (ZPA9) "ecossistema de dunas e lagoas ao longo do Rio Doce" (Figura 3).

O discurso dos seus moradores mostra a importância dos recursos naturais da área para a reprodução da agricultura no local. Na fala do morador Adauto Alves, se percebe a importância das lagoas para a região: "Na beira da Lagoa Azul. (...) Se não fosse a lagoa, não dava certo. Não existia poço, não existia, era a Lagoa Azul para trabalhar" (ALVES, 2012, p. 117).

Figura 3: Recursos naturais e potencial Cênico-paisagístico da ZPA 9.

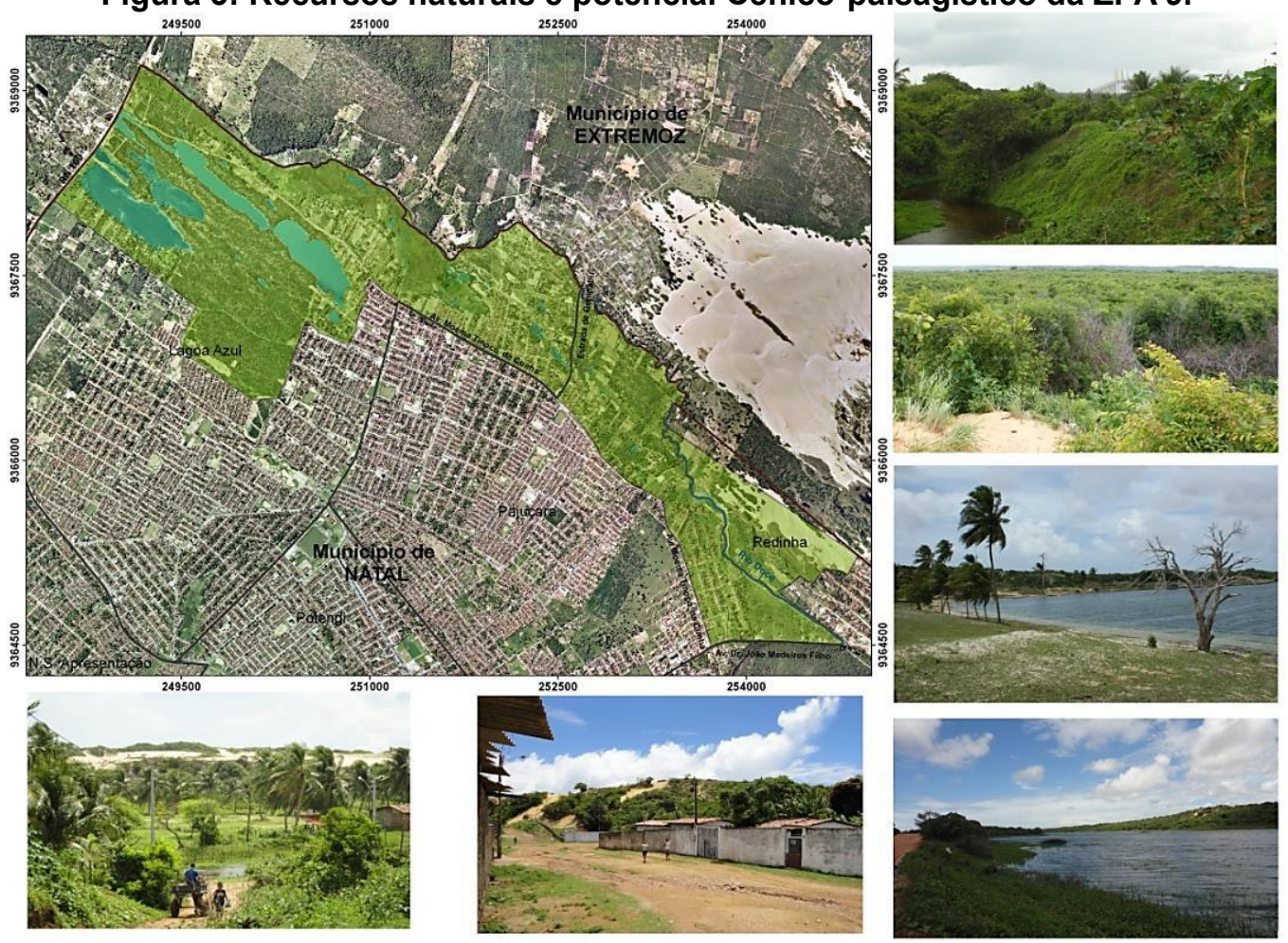

Fonte: MPRN, 2012. Modificado pelas autoras.

Apesar de suas características tipicamente rurais, o Gramorezinho é classificado no Plano Diretor como uma área urbana. Há dois motivos que podem 
explicar esta classificação: primeiro, a arrecadação municipal de impostos, que só pode ser realizada caso a área seja classificada como urbana; segundo; o valor superior da terra urbana frente à rural, o que atende aos interesses do mercado imobiliário. No entanto, esta situação dificulta o acesso a crédito bancário e financiamentos voltados para produtores rurais pela comunidade.

Porém, a legislação também o classifica como Área Especial de Interesse Social (AEIS) voltada para a Segurança Alimentar. Segundo o Plano, as AEIS são delimitadas por suas configurações morfológicas, sociais, culturais e econômicas e nelas a renda familiar predominante é de até três salários mínimos (NATAL, 2007, Art.6ำ VII). Contudo a AEIS 3, na qual o Gramorezinho e outras áreas agrícolas da cidade se inserem, ainda carece de delimitação e regulamentação específica. Esta regulamentação deve acontecer com participação popular e, enquanto não for finalizada, remembramentos e desmembramentos de terrenos e construções acima de 7,5 metros ficam proibidos na área. A regularização do Gramorezinho como AEIS, deixando claras suas especificidades, poderia facilitar o acesso a programas de apoio financeiro para a produção.

No ano de 2012, uma ação de assistência técnica em parceria com os produtores teve início no Gramorezinho. Trata-se do Projeto Amigo Verde, iniciativa do Ministério Público do RN em parceria com a SEMURB ${ }^{10}, E$ EMATER $^{11} \mathrm{RN}$, SEBRAE $^{12}$ RN e UFRN. Este projeto tem com objetivo fomentar a produção orgânica na comunidade a fim de minimizar os impactos socioambientais causados pelo uso de agrotóxicos e adubos químicos antes utilizados. A agricultura orgânica é um sistema de manejo sustentável que prioriza a proteção ambiental e utiliza técnicas como a rotação de culturas e a compostagem. Segundo dados do projeto, até 2014 cerca de 30 agricultores haviam recebido o selo de produção orgânica fornecido pelo Ministério da Agricultura (MINISTÉRIO PÚBLICO, 2014).

Atualmente, os produtores realizam feiras orgânicas em diversas localidades da cidade, nas quais é possível auferir um lucro maior devido à venda direta ao consumidor. Além da preocupação com o meio ambiente, o projeto também busca

\footnotetext{
${ }^{10}$ Secretaria de Meio Ambiente e Urbanismo vinculada à Prefeitura de Natal.

${ }^{11}$ Empresa de Assistência Técnica e Extensão Rural.

12 Serviço Brasileiro de Apoio à Micro e Pequenas Empresas.
} 
incentivar o empreendedorismo, através de capacitação dada pelo SEBRAE, e a cooperação entre os agricultores, que se reúnem semanalmente para decidir sobre a realização das feiras e discutir questões relacionadas ao projeto. A existência do Projeto Amigo Verde, tendo a sua frente instituições públicas e privadas, demonstra o reconhecimento da importância da agricultura para o Gramorezinho e da própria comunidade em si para a cidade de Natal. O projeto comprova ainda que a compatibilidade entre a produção de hortaliças e a proteção ambiental é possível.

No entanto, conflitos que podem impactar a comunidade são verificados na área, sendo o mais evidente deles o Projeto Pró-Transporte. O projeto, que se encontra sob a responsabilidade do Governo do Estado do RN, apresenta proposta de reestruturação para a Avenida Moema Tinoco, na qual se situam os produtores do Gramorezinho. Esta avenida possui um papel importante como eixo de interligação entre o litoral norte e o litoral sul da Região Metropolitana de Natal e, por isso, propõe-se a sua duplicação e a implantação de terminal de $B R T^{13}$ na via. Para isto, os produtores do Gramorezinho teriam parte dos seus terrenos desapropriada.

Apesar de a reestruturação da via ser importante, é necessário medir os tipos de impactos sociais decorrentes da sua duplicação. Se por um lado o projeto traz benefícios para a comunidade - como a possibilidade de circulação de linhas de ônibus mais perto de suas residências -, por outro pode acarretar consequências negativas, descaracterizando a área e causando prejuízos diretos aos produtores.

Além da necessidade de reestruturação viária e da demanda por transporte público na região, em reuniões realizadas com os moradores foi verificada também a demanda por espaços públicos destinados ao lazer, praticamente inexistentes na comunidade. Ademais, foram apontadas outras dificuldades mais relacionadas a produção e comercialização das hortaliças e articulação comunitária, como a falta de comunicação entre os produtores e a preferência dos consumidores por produtos mais baratos e de melhor aparência aos orgânicos.

Sendo assim, apesar do sucesso do Projeto Amigo Verde, outras políticas públicas precisam ser pensadas para a área. A regulamentação do Gramorezinho

\footnotetext{
${ }^{13}$ Bus Rapid Transit, sistema de operação que utiliza corredores exclusivos para ônibus para promover o seu rápido deslocamento.
} 
como AEIS poderá contribuir neste sentido, uma vez que o processo exige um quadro descritivo de obras de urbanização e paisagismo necessárias para a área. Além disso, seu reconhecimento legal na regulamentação da ZPA 9, permitirá a permanência da comunidade no local e a continuidade da prática da agricultura urbana, acompanhada dos diversos benefícios sociais, ambientais, culturais e econômicos que a atividade apresenta.

\section{CONSIDERAÇÕES FINAIS}

A partir das reflexões apresentadas, é possível afirmar que o Gramorezinho é um exemplo singular de como as atividades econômicas podem estar em consonância com a as estratégias de gestão e planejamento ambiental. Além disso, a comunidade apresenta características que contribuem para a sustentabilidade urbana em Natal.

As atividades desenvolvidas no Gramorezinho dialogam com o conceito de biofilia definidos por Farr (2013), pela prática da agricultura orgânica e preocupação com o meio ambiente, observados na área, e de infraestrutura verde discutido por Herzog (2013), mais especificamente como exemplo ação vinculada ao sistema metabólico, contribuindo para o abastecimento alimentar urbano. Além disso, a atividade possui importância socioeconômica e ambiental, pois além de ser a fonte de renda dos produtores, estimula o comércio local e contribui para o aumento de áreas verdes na cidade. Cabe ainda frisar o papel que a comunidade exerce do ponto de vista cultural, resguardando relações com a terra com os citadinos.

Além do Projeto Amigo Verde, o estabelecimento de outras políticas públicas para a área pode contribuir para aprofundar a sintonia do lugar com o conceito da sustentabilidade urbana. A provisão da infraestrutura necessária à comunidade, como transporte público e os espaços de lazer, poderá atrair também outros serviços para o local, tornando-a mais diversa. Também se faz necessário que seja dada voz à população local nos processos decisórios relacionados ao desenvolvimento da área. 
Por estes fatores, o Gramorezinho deve ser reconhecido e protegido através de sua regulamentação como AEIS de Segurança Alimentar e incluso na regulamentação da ZPA 9, pois a proteção ambiental e a justiça social devem caminhar juntas para a construção de uma cidade verdadeiramente sustentável.

\section{REFERÊNCIAS}

ALVES, Adauto Severino. Depoimento sobre o bairro de Lagoa Azul. Natal, out. 2012. CAPISTRANO, Luciano Fábio Dantas; COSTA, Matheus Câmara da; PINHEIRO, Marina Dantas; MACEDO, Gabriela Cavalcanti; SILVA, Tyego Franklim da. Memória minha comunidade: Lagoa Azul. Natal: SEMURB, 2013. p. 117. Entrevista concedida a Luciano F. Dantas Capistrano, Marina Dantas Pinheiro e Matheus Câmara da Costa.

AMÉRICO, Maria Conceição Oliveira. Processos sócio-ambientais relacionados às situações de degradação na região do Rio Doce, Natal/RN. Natal, RN: 2006. 100 f. Dissertação (Mestrado) Universidade Federal do Rio Grande do Norte. Centro de Biociências. Programa de Pós-Graduação em Desenvolvimento e Meio Ambiente.

COMISSÃO MUNDIAL SOBRE MEIO AMBIENTE E DESENVOLVIMENTO. Nosso Futuro Comum. 2. ed. Rio de Janeiro: Fundação Getúlio Vargas, 1988.

FARR, Douglas. Urbanismo Sustentável: desenho urbano com a natureza. Porto Alegre: Bookman, 2013.

HERZOG, Cecilia Polacow. Cidades para Todos: (re)aprendendo a conviver com a natureza. Rio de Janeiro: Mauad X: Inverde, 2013.

IMBERT, Dorothée. Às fazendas, cidadãos! IN: MOSTAFAVI, Mohsen; DOHERTY, Gareth (org.). Urbanismo ecológico. São Paulo: Gustavo Gili, 2014. p. 256-267.

LEFEBVRE, Henri. O direito à cidade. São Paulo: Centauro, 2001.

LERNER, Jaime. Acupuntura Urbana. 5. ed. Rio de Janeiro: Record, 2011.

MADALENO, Isabel Maria. A cidade das Mangueiras: agricultura urbana em Belém do Pará. Lisboa: Fundação Calouste Gulbenkian, 2002.

MINISTÉRIO PÚBLICO DO RIO GRANDE DO NORTE. Projeto Amigo Verde - Gramorezinho. Publicado em 22 de maio de 2014. Disponível em: <http://www.mprn.mp.br/portal/meio-ambientecampanhas-e-eventos/110-meio-ambiente/meio-ambiente-campanhas-e-eventos/6181-projeto-amigoverde-gramorezinho>. Acesso em: 17 abr 2014.

MOUGEOT, Luc J. A. Agricultura urbana: conceito e definição. Revista de Agricultura Urbana. Holanda, v.1, n.1, jul. $2000 . \quad$ Disponível $\quad$ em: <http://agriculturaurbana.org.br/RAU/AU01/AU1conceito.html>. Acesso em: 13 abr, 2015.

NATAL. Câmara Municipal. Lei Complementar № 082, de 21 de junho de 2007. Dispõe sobre o Plano Diretor de Natal e dá outras providências. Natal, 2007. 


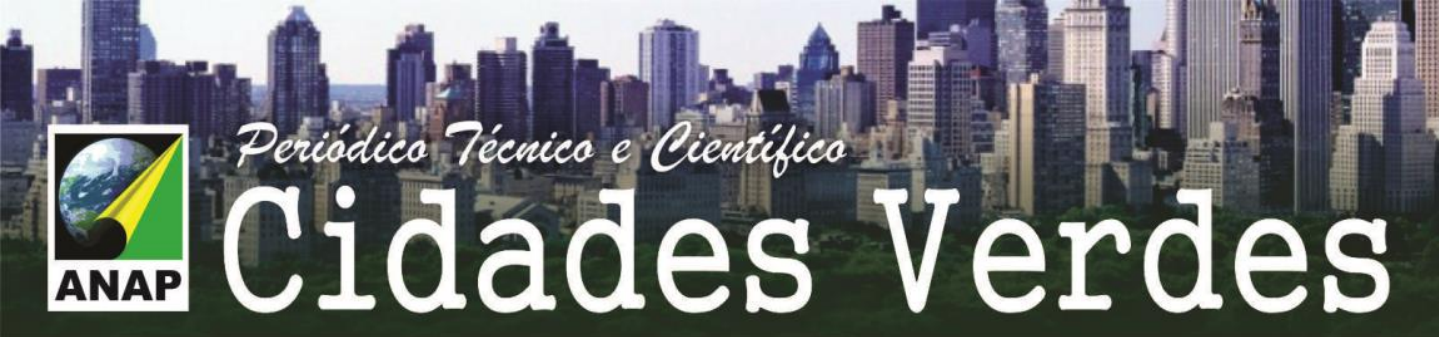

NOVAES, Washington (Coord.). Agenda 21 Brasileira: bases para discussão. Brasília: MMA/PNUD, 2000.

PINTO, Rute Sofia Borlido Fiúza Fernandes. Hortas Urbanas: Espaço para o Desenvolvimento Sustentável de Braga. 2007. Dissertação (Mestrado em Engenharia Municipal) - Escola de Engenharia, Universidade do Minho, Braga, 2007.

SANTANDREU, Alain; LOVO; Ivana Castro. Panorama da Agricultura Urbana e Periurbana no Brasil e Diretrizes Políticas para sua Promoção: Identificação e Caracterização de Iniciativas de AUP em Regiões Metropolitanas Brasileira. Belo Horizonte: FAO: MDS, 2007.

UNITED NATIONS. Department of Economic and Social Affairs. Word Urbanization Prospects: highlights. 2014 Revision. (2014). Disponível em: <http://esa.un.org/unpd/wup/Highlights/WUP2014Highlights.pdf>. Acesso em: 7 abr. 2015.

UNIVERSIDADE FEDERAL DO RIO GRANDE DO NORTE. Implicações ambientais e urbanísticas decorrentes das propostas de regulamentação da Zona de Proteção Ambiental 9 (ZPA 9), município de Natal/RN. Laudo pericial solicitado pelo Ministério Público do Estado do Rio Grande do Norte à Universidade Federal do Rio Grande do Norte. Natal: UFRN, 2012.

ZAAR, Miram-Hermi. Agricultura Urbana: algunas reflexiones sobre su origen e importancia actual. Revista Bibliográfica de Geografía y Ciencias Sociales. Barcelona, v. XVI, n. 944, out. 2011. Disponível em: <http://www.ub.edu/geocrit/b3w-944.htm>. Acesso em: 20 abr. 2014. 